\title{
The Effects of Gasotransmitters Inhibition on Homocysteine Acutely Induced Changes in Oxidative Stress Markers in Rat Plasma
}

\section{Marko Djuric ${ }^{1}$, Sanja Kostic², Dragana Loncar-Stojiljkovic 3 , Slavica Mutavdzin ${ }^{4}$, Mirjana B. Colovic ${ }^{5}$, Danijela Krstic ${ }^{6}$, Predrag Stevanovic ${ }^{1}$ and Dragan M. Djuric ${ }^{4}$}

\begin{abstract}
Background: The importance of homocysteine (Hcy) is increasingly recognized in last few decades as an independent risk factor for atherosclerosis and thrombosis, but there is lack of data referring to influence of Hcy on plasma oxidative stress parameters as well as the role of gasotransmitters in these effects. Therefore, this study aim was to assess the role of gasotransmitter inhibitors in Hcy-induced effects on plasma oxidative stress in rats.

Material and Methods: Study involved 96 male Wistar albino rats divided into 8 groups: 1) Control group - saline (1ml $0.9 \% \mathrm{NaCl}$ i.p.); 2) DL-Hcy $(8 \mathrm{mmol} / \mathrm{kg}$ i.p. DL homocysteine (DL-Hcy); 3) L-NAME (10 mg/kg i.p. N $\omega$-Nitro-L-arginine methyl ester (L-NAME), inhibitor of NO production); 4) ZnPPR IX (30 $\mu \mathrm{mol} / \mathrm{kg}$ i.p. protoporphyrin IX zinc (ZnPPR IX), inhibitor of CO production); 5) DL-PAG (5O mg//kg i.p. DL-propargylglycine (DL-PAG), inhibitor of H2S production); 6) DL-Hcy+L-NAME ( $8 \mathrm{mmol} / \mathrm{kg}$ i.p. DL-Hcy $+10 \mathrm{mg} / \mathrm{kg}$ i.p. L-NAME); 7) DL-Hcy+ZnPPR IX ( $8 \mathrm{mmol} / \mathrm{kg}$ i.p. DL-Hcy $+30 \mu \mathrm{mol} / \mathrm{kg}$ i.p. Zn PPR IX), and 8$)$ DL-Hcy+DL-PAG ( $8 \mathrm{mmol} / \mathrm{kg}$ i.p. DL-Hcy $+50 \mathrm{mg} / / \mathrm{kg}$ i.p. DL-PAG). In all experimental groups, tested substances were administered in a single dose, intraperitoneally, 6o minutes before animals' euthanasia. In the collected blood samples malondialdehyde concentration, catalase, glutathione peroxidase and superoxide dismutase activity were measured.

Results: Applied substances induced rapid and strong increase of plasma antioxidant enzymatic activity probably as a compensatory response to its pro-oxidant influence.
\end{abstract}

Conclusion: The effects of Hcy on the activity of plasma antioxidant enzymes are in part mediated via interaction with gasotransmitters.

Key words: gasotransmitters, homocysteine, oxidative stress markers, rat plasma.
(1) Department of Anesthesiology, Reanimatology and Intensive Care Medicine, University Clinical Hospital Center "Dr. Dragiša Mišović - Dedinje", Belgrade, Serbia

(2) Faculty of Medicine, University of Belgrade, Belgrade, Serbia

(3) Institute for Cardiovascular Diseases "Dedinje", Belgrade, Serbia

(4) Institute of Medical Physiology "Richard Burian", Faculty of Medicine, University of Belgrade, Belgrade, Serbia

(5) Department of Physical Chemistry, Vinča Institute of Nuclear Sciences, University of Belgrade, Belgrade, Serbia

(6) Institute of Chemistry in Medicine "Prof. Dr. Petar Matavulj", Faculty of Medicine, University of Belgrade, Belgrade, Serbia

\section{Correspondence:}

DRAGAN M. DJURIC

E: drdjuric@eunet.rs

E: dr_djuric@yahoo.com

\section{ARTICLE INFO}

Received: $9^{\text {th }}$ January 2019 Revision received: $5^{\text {th }}$ February 2019 Accepted: $12^{\text {th }}$ February 2019

\section{INTRODUCTION}

Homocysteine (Hcy) is a S-containing amino acid and its plasma concentrations can be raised by various constitutive, genetic and lifestyle factors. Hyperhomocysteinaemia is a modest independent predictor (risk factor or marker) of cardiovascular disease, stroke, neurodegeneration and cancer. ${ }^{1,2}$ Some recent studies have shown that Hcy toxicity is mainly caused by oxidative stress via increasing inflammatory response ${ }^{3}$ and augmenting reactive oxygen species (ROS). ${ }^{4} \mathrm{Hy}-$ perhomocysteinemia is related with increased ROS formation, including the superoxide anion radical (O2-) and hydrogen peroxide ( $\left.\mathrm{H}_{2} \mathrm{O} 2\right){ }^{5}$ and in that way it leads to oxidative stress and 
cellular damage. ${ }^{6}$ Oxidative stress may influence the endogenous antioxidant system that includes glutathione-dependent enzymes (glutathione peroxidase (GPx), glutathione reductase (GR) and glutathione-S-transferase (GST)), superoxide dismutase (SOD), and catalase (CAT) antioxidant enzymes. ${ }^{6,7}$ There is a evidence that hyperhomocysteinemia may impair the glutathione-related antioxidant defense system, ${ }^{8,9}$ however data about its effect on SOD activity are still controversial. Wilcken et al. have revealed a positive correlation between SOD activity and Hcy levels in patients with homocystinuria, ${ }^{10}$ while other authors showed that hyperhomocysteinemia decreased erythrocyte SOD activity in patients with cardiovascular disease..$^{9,1}$

On the other hand, there are increasing number of assumptions that signaling gaseous molecules as nitric oxide (NO), carbon monoxide (CO) and hydrogen sulfide $\left(\mathrm{H}_{2} \mathrm{~S}\right)^{12}$ may have an important role in effects of Hcy-thiolactone on the myocardial function and coronary circulation. ${ }^{13}$ This is very plausible having in mind that gasotransmitters have an important role in the regulation of inflammation, oxidative stress, modulation of mitochondria respiration and activation of antioxidant enzymes. ${ }^{14}$ With participation of NO, S-nitroso-Hcy inhibits hydrogen peroxide. ${ }^{15}$ $\mathrm{H} 2 \mathrm{~S}$ also decreases level of Hcy in plasma ${ }^{16}$ and it is strong antioxidant. ${ }^{17} \mathrm{CO}$ is the most stable gasotransmitter, and it is capable of exerting its effects during long time and distances. ${ }^{18}$

However, Hcy-thiolactone and gasotransmitters connection is still not fully understood. Thus, the aim of this research was to examine the effects of acute administration of DL-Hcy alone or in combination with specific inhibitors of different gasotransmitters, such as N $\omega$-nitro-L-arginine methyl ester (L-NAME), Zinc protoporphyrin IX (ZnPPR IX) and DL-Propargyl Glycine (DL-PAG) on oxidative stress markers in the rat plasma - catalase (CAT), superoxide dismutase (SOD), glutatione peroxidase (GPx) activities and malondialdehyde (MDA) concentration.

\section{METHODS}

Physiological Assay and Experimental Protocol Male Wistar albino rats ( $n=96,12$ in each exper- imental group, 10 weeks old, body weight (250 \pm $30 \mathrm{~g}$ ) have been used for investigation. Animals were housed in strictly controlled conditions (air temperature of $22 \pm 1^{\circ} \mathrm{C}$, relative humidity of 50\%, a cycle of brightness: darkness 12:12 hours, starting bright period at $8 \mathrm{AM}$ ), with free access to water and standard food. In all experimental groups, tested substances were administered in a single dose, intraperitoneally (i.p.), 60 minutes before euthanasia of animals. All animals were divided into 8 groups, and received: 1) Control group - saline (1 ml 0.9\% NaCl i.p., $\mathrm{pH} 7.4) ; 2$ ) DL-Hcy group ( $8 \mathrm{mmol} / \mathrm{kg}$ i.p. DL homocysteine); 3) L-NAME group (10 mg/kg i.p. L-NAME as inhibitor of NO production via inhibition of nitric oxide synthase); 4) ZnPPR IX group (30 $\mu \mathrm{mol} / \mathrm{kg}$ i.p. ZnPPR IX as inhibitor of CO production via inhibition of heme oxygenase-1); 5) DL-PAG group (50 mg//kg i.p. DL-PAG as inhibitor of $\mathrm{H} 2 \mathrm{~S}$ production via inhibition of cystathionine gamma lyase); 6) DL-Hcy+L-NAME group $(8 \mathrm{mmol} / \mathrm{kg}$ i.p. DL-Hcy $+10 \mathrm{mg} / \mathrm{kg}$ i.p. L-NAME); 7) DL-Hcy+ZnPPR IX group (8 $\mathrm{mmol} / \mathrm{kg}$ i.p. DL-Hcy $+30 \mu \mathrm{mol} / \mathrm{kg}$ i.p. ZnPPR IX), and DL-Hcy+DL-PAG group ( $8 \mathrm{mmol} / \mathrm{kg}$ i.p. DL-Hcy $+50 \mathrm{mg} / / \mathrm{kg}$ i.p. DL-PAG).

All experimental procedures were done in accordance with prescribed legislation (EU Directive for the Protection of Vertebrate Animals used for Experimental and other Scientific Purposes 86/609/EES) and the principles of ethics.

\section{Biochemical analyses}

Sixty minutes after administration of tested substances, the rats were euthanized by decapitation. Blood was collected through a glass funnel and placed in test tubes coated in heparin. The blood samples were left at the room temperature for $15 \mathrm{~min}$ and afterwards centrifuged (15 $\min \times 3000 \mathrm{rpm})$. The obtained plasma was used for the analyses.

The evaluated parameters were determined in the control condition, and then in acute series of experiments.

\section{Determination of Hcy}

The plasma samples were analyzed using the electrochemiluminescence method (ECL- electrochemiluminescence immunoassay system, ADVIA Centaur XP System, Siemens Healthcare $\mathrm{GmbH}$, Erlangen, Germany); the range of reference values was $\mathrm{Hcy}<15 \mu \mathrm{mol} / \mathrm{l}$. 
Determination of lipid peroxidation products (MDA) MDA content in plasma was determined by using of thiobarbituric assay. ${ }^{14} 500 \mathrm{ml}$ of $25 \% \mathrm{HCl}$ and $500 \mathrm{ml}$ of $1 \%$ thiobarbituric acid (in $50 \mathrm{mM}$ $\mathrm{NaOH}$ ) was added in $500 \mathrm{ml}$ of sample. The mixture was heated for 10 minutes on boiling water bath, and cooled to room temperature. Then $3 \mathrm{~mL}$ of n-butanol was added and shaken on a Vortex for 30 seconds. In order to successfully separate phases, samples are centrifugated (10 minutes at $2000 \times \mathrm{g}$ ). Content of malondialdehyde was determined spectrophotometrically by measuring the absorbance of the organic phase (upper layer) at $532 \mathrm{~nm}$. The blanks contain 50 $\mathrm{mM} \mathrm{NaOH}$ instead of thiobarbituric acid, and they are prepared for each sample separately. The values of MDA content ( $\mathrm{nmol}$ of MDA/ml plasma) was determined on the basis of absorbance values and molar absorption coefficient of the malondialdehyde-thiobarbituric acid complex.

\section{Determination of CAT activity}

CAT activity was measured by an essay that accompanies the degradation of $\mathrm{H}_{2} \mathrm{O} 2$ according to Beutler. ${ }^{19} 50 \mu \mathrm{l}$ of a suspension of plasma was added to the quartz glass tubes at room temperature, consisting of $2.975 \mathrm{ml}$ of $50 \mathrm{mM}$ phosphate buffer solution in $0.4 \mathrm{mM}$ EDTA. The enzyme reaction is initiated by adding $30 \mu \mathrm{O}$ of $3 \% \mathrm{H}_{2} \mathrm{O} 2$. Reduction in absorbance due to enzymatic degradation of $\mathrm{H}_{2} \mathrm{O}_{2}$ (at $240 \mathrm{~nm}$ for $3-5$ minutes) was monitored. CAT activity was expressed as $\mathrm{U} / \mathrm{ml}$ of plasma. One unit (U) of enzyme activity was defined as 1 micromol of spent $\mathrm{H}_{2} \mathrm{O} 2 / \mathrm{min}$.

\section{Determination of SOD activity}

The activity of total SOD was measured according to the method of Misra and Fridovich.20 10$30 \mu \mathrm{l}$ of plasma was added in $3 \mathrm{ml}$ of a $0.5 \mathrm{M}$ EDTA-sodium carbonate buffer $(\mathrm{pH}$ 10.2). The enzymatic reaction started by adding $100 \mathrm{ml}$ of epinephrine (30 $\mathrm{mM}$ in $0.1 \mathrm{M} \mathrm{HCl}$ ). SOD activity was measured at absorbance of $480 \mathrm{~nm}$ during 4 minutes. One unit (U) of SOD was defined as the amount of enzyme that inhibits the rate of the epinephrine oxidation for 50\%. The enzyme activity was expressed as $\mathrm{U} / \mathrm{ml}$ of plasma.

\section{Determination of GPx activity}

Procedure for measuring of GPx activity begins with preparation of reaction cocktail which consists of $8.9 \mathrm{ml}$ of phosphate buffer, $50 \mu \mathrm{l}$ of 200 $\mathrm{mM}$ reduced glutathione (GSH), $1 \mathrm{mg}$ of $\beta$-NA$\mathrm{DPH}$, and $100 \mathrm{ml}$ of 100 units/ml GSH-reductase from baker's yeast (Saccharomyces cerevisi- ae). $\mathrm{pH}$ value of reaction cocktail was adjusted to 7 (50 mM NaH2PO4 + 0.40 mM EDTA). $3 \mathrm{ml}$ of a reaction cocktail and $0.3 \mathrm{ml}$ of plasma sample was added in a quartz glass cuvette (room temperature). Cuvette was placed in a spectrophotometer, and $50 \mathrm{ml}$ of $0.042 \% \mathrm{H}_{2} \mathrm{O} 2$ was added in order to start enzymatic reaction (A240 $=0.52$ to 0.56$)$. The decline of absorbance $(\lambda=340 \mathrm{~nm})$ in intervals of 15 seconds during the 4-5 minutes was monitored. GPx activity was expressed as $\Delta \mathrm{A} / \mathrm{min} / \mathrm{ml}$ of plasma. ${ }^{21}$.

\section{Chemicals used}

All chemicals were of p.a. grade quality and were purchased from Sigma Aldrich (Germany).

\section{Statistical analyses}

The parameters of descriptive statistics were used. For testing statistical significance after testing normality of distribution, one-way analysis of variance (ANOVA), followed by Tukey's Post Hoc Test was used. Statistical calculation was done using SPSS computer program (SPSS Inc. Chicago, SAD). Values are presented as mean \pm SEM. $\mathrm{P}<0.05$ was considered statistically significant.

\section{RESULTS}

\section{Determination of Hcy}

In all plasma samples levels of measured Hcy were more than $65 \mu \mathrm{mol} / \mathrm{l}$, indicating moderate hyperhomocysteinemia (30-100 $\mu \mathrm{mol} / \mathrm{l})$, except in the Control group in which it was $10.4 \pm 0.6$ $\mu \mathrm{mol} / \mathrm{l}$.

\section{Plasma MDA values}

In all experimental groups: DL-Hcy $(6.09 \pm 0.85$ $\mathrm{nmol} / \mathrm{ml}$ of plasma, Figure 1. a), L-NAME $(5.63 \pm 0.85 \mathrm{nmol} / \mathrm{ml}$ of plasma, Figure 1. a), DLPAG $(5.28 \pm 1.37 \mathrm{nmol} / \mathrm{ml}$ of plasma, Figure $1 . \mathrm{a})$, DL-Hcy+L-NAME $(4.10 \pm 0.74 \mathrm{nmol} / \mathrm{ml}$ of plasma, Figure 1. b), DL-Hcy+ZnPPR IX (4.28 \pm 0.59 $\mathrm{nmol} / \mathrm{ml}$ of plasma, Figure $1 . \mathrm{b})$, DL-Hcy+DL PAG $(9.90 \pm 0.94 \mathrm{nmol} / \mathrm{ml}$ of plasma, Figure 1. b), except ZnPPR IX alone (17.30 $\pm 4.74 \mathrm{nmol} /$ ml of plasma, Figure 1. a), the administration of tested substances induced significant decrease in MDA values compared with control condition $(15.37 \pm 1.41 \mathrm{nmol} / \mathrm{ml}$ of plasma) (Figure $1 \mathrm{a}, \mathrm{b})$.

\section{Plasma CAT activity}

In relation to control group $(16.40 \pm 2.11 \mathrm{U} / \mathrm{ml}$ of plasma, Figure 2. a, b), the administration of all 
tested substances induced significant increase in CAT activity: L-NAME $(50.59 \pm 3.58 \mathrm{U} / \mathrm{ml}$ of plasma, Figure 2. a), ZnPPR IX (67.54 \pm 2.08 $\mathrm{U} / \mathrm{ml}$ of plasma, Figure 2. a), DL- PAG $(118.69 \pm 12.13 \mathrm{U} / \mathrm{ml}$ of plasma, Figure 2 . a), DLHcy+L-NAME $(127.87 \pm 19.17 \mathrm{U} / \mathrm{ml}$ of plasma, Figure 2. b), DL-Hcy+ZnPPR IX (181.19 \pm 16.64 $\mathrm{U} / \mathrm{ml}$ of plasma, Figure 2. b), DL-Hcy+DL-PAG (109.58 $22.43 \mathrm{U} / \mathrm{ml}$ of plasma, Figure 2. b), however only in DL-Hcy group (26.49 $\pm 4.22 \mathrm{U} /$ $\mathrm{ml}$ of plasma, Figure 2. a) there was no significant change in this parameter.

\section{Plasma GPx activity}

Levels of GPx were significantly increased by all of the applied substances: L-NAME $(3 \cdot 37 \pm 0.23$ $\mathrm{U} / \mathrm{ml}$ of plasma, Figure 3. a), ZnPPR IX $(4.50 \pm 0.13 \mathrm{U} / \mathrm{ml}$ of plasma, Figure $3 . \mathrm{a})$, DLPAG (7.91 $\pm 0.80 \mathrm{U} / \mathrm{ml}$ of plasma, Figure 3. a), DL-Hcy+L-NAME $(7.60 \pm 0.77 \mathrm{U} / \mathrm{ml}$ of plasma,
Figure 3. b), DL-Hcy+ZnPPR IX (12.59 \pm 0.69 $\mathrm{U} / \mathrm{ml}$ of plasma, Figure 3. b), DL-Hcy+DL-PAG $(6.37 \pm 0.72 \mathrm{U} / \mathrm{ml}$ of plasma, Figure $3 . \mathrm{b})$, except DL-Hcy alone $(1.76 \pm 0.28 \mathrm{U} / \mathrm{ml}$ of plasma, Figure 3. a), compared with control condition $(1.09 \pm 0.14 \mathrm{U} / \mathrm{ml}$ of plasma, Figure $3 . \mathrm{a}, \mathrm{b})$.

\section{Plasma SOD activity}

Administration of all tested substances: DLHcy (30.41 $\pm 0.71 \mathrm{U} / \mathrm{ml}$ of plasma, Figure 4. a), L-NAME $(31.07 \pm 0.40 U / \mathrm{ml}$ of plasma, Figure 4 . a), DL-PAG $(30.25 \pm 0.54 \mathrm{U} / \mathrm{ml}$ of plasma, Figure 4. a), DL-Hcy+L-NAME (32.98 $\pm 0.94 \mathrm{U} /$ $\mathrm{ml}$ of plasma, Figure 4. b), DL-Hcy+ZnPPR IX $(33.36 \pm 0.43 \mathrm{U} / \mathrm{ml}$ of plasma, Figure 4 . b), DLHcy+DL-PAG $(32.66 \pm 1.20 \mathrm{U} / \mathrm{ml}$ of plasma, Figure 4 . b) caused significant increase in SOD level compared with control condition $(25.31 \pm 0.96$ $\mathrm{U} / \mathrm{ml}$ of plasma, Figure 4. a, b), except ZnPPR IX alone $(26.46 \pm 2.65 \mathrm{U} / \mathrm{ml}$ of plasma, Figure 4 . a).
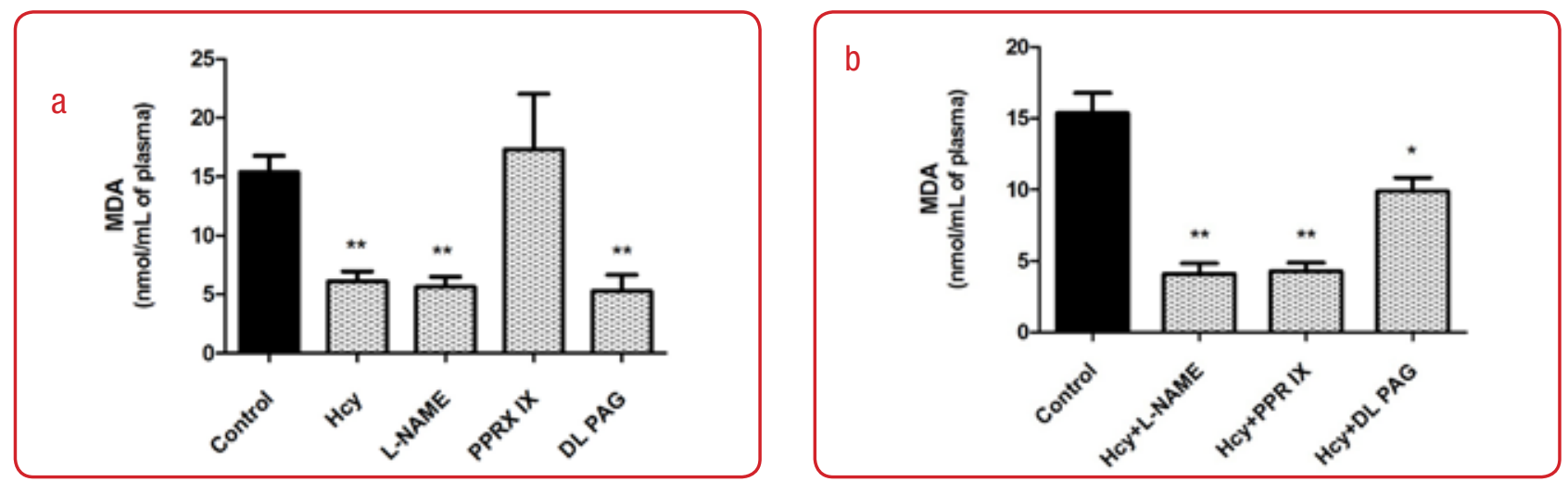

Figure 1. The effects of Hcy and gasotransmitters inhibition separately (a) and its combination (b) on MDA concentration in rat plasma. Values are presented as mean $\pm \mathrm{SEM}$. ${ }^{*} \mathrm{P}<0.05 ;{ }^{* \star} \mathrm{P}<0.01$ compared to control group.
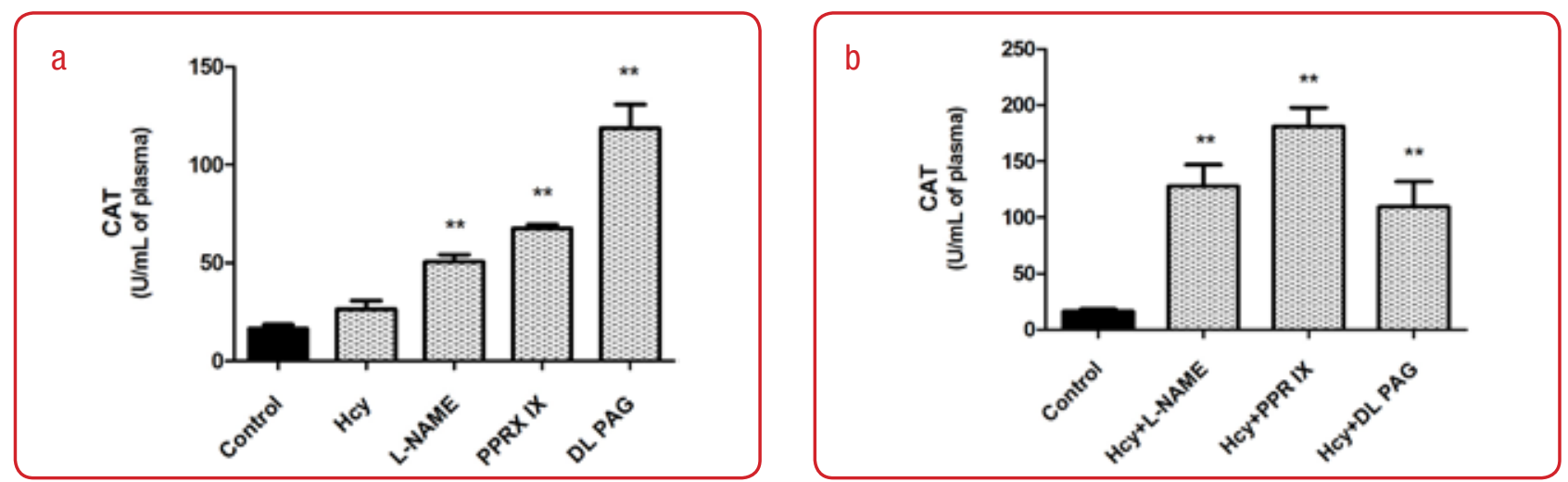

Figure 2. The effects of Hcy and gasotransmitters inhibition separately (a) and its combination (b) on CAT activity in rat plasma. Values are presented as mean $\pm \mathrm{SEM} .{ }^{* \star P}<0.01$ compared to control group. 

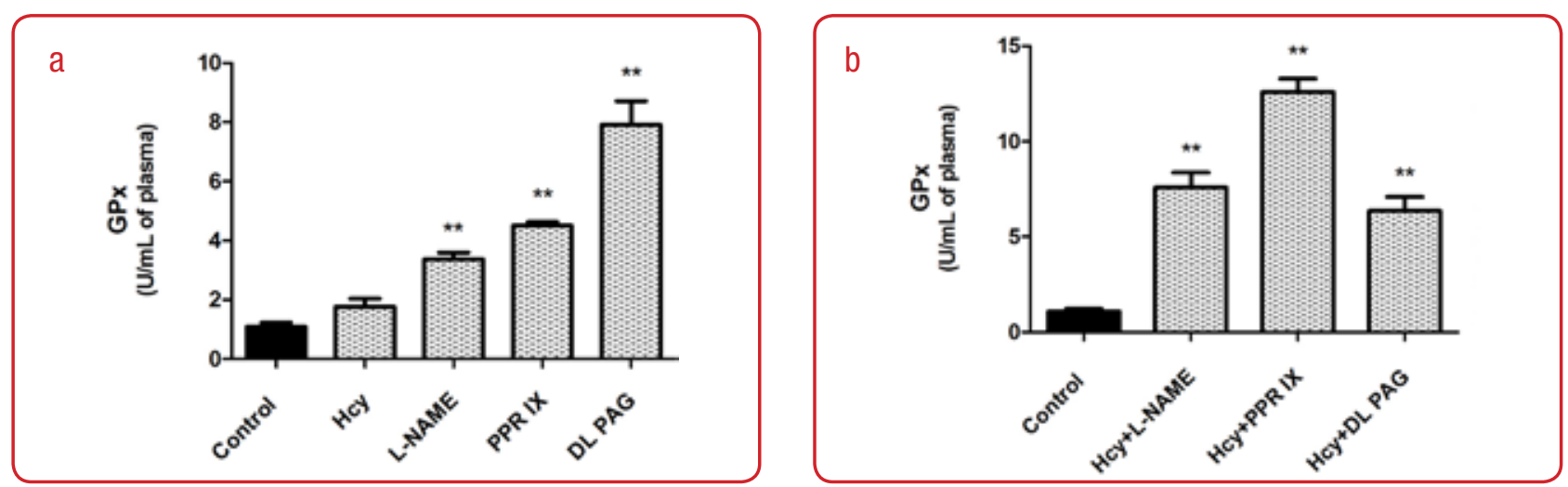

Figure 3. The effects of Hcy and gasotransmitters inhibition separately (a) and its combination (b) on GPx activity in rat plasma. Values are presented as mean \pm SEM. ${ }^{* *} \mathrm{P}<0.01$ compared to control group.
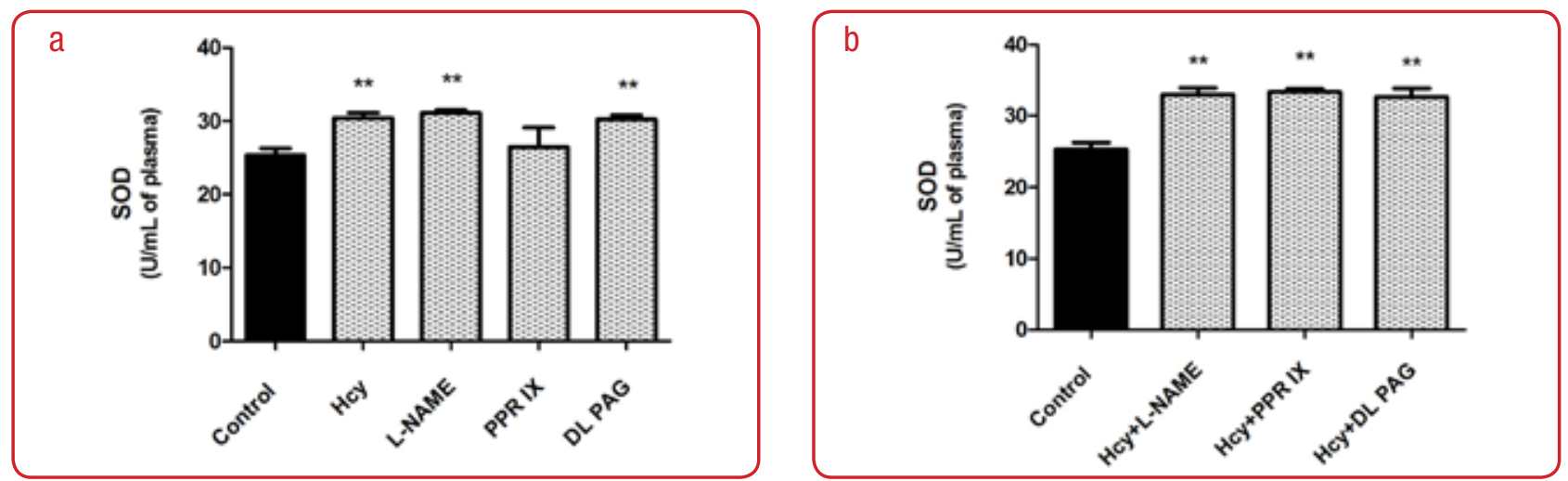

Figure 4. The effects of Hcy and gasotransmitters inhibition separately (a) and its combination (b) on SOD activity in rat plasma. Values are presented as mean $\pm \mathrm{SEM} .{ }^{* *} \mathrm{P}<0.01$ compared to control group.

\section{DISCUSSION}

In present investigation DL-Hcy caused decrease of MDA level in the plasma, indicating that acutely applied Hcy does not increase lipid peroxidation in plasma of rats. Similar results were observed in case of $\mathrm{NO}$ or $\mathrm{H} 2 \mathrm{~S}$ inhibition, or during synergistic application of each inhibitor with Hcy. Therefore, we can assume that (except CO) gaseous molecules could induce plasma lipid peroxidation, while in presence of Hcy positive effect of their blockage seems to be even more obvious. Decreased level of MDA in all groups may be consequence of increased activities of antioxidant enzymes in same groups during the same time. We previously noted that thiolactone form of Hcy alone or in combination with gasotransmitter inhibitors non-significantly decreased level of lipid peroxidation measured in coronary venous effluent. ${ }^{13}$

In the second part of our research, we focused on the effects of Hcy and different gasotransmitters production inhibition and on antioxidative enzyme system such as GPx, CAT, SOD. The ob- tained results have shown that acute intraperitoneal administration of DL-Hcy induced acute increase of antioxidative enzymatic activity, which correlates with decreased values of MDA. These findings probably mean that DL-Hcy induce strong pro-oxidant effects taking into consideration rapid and significant increased activities of antioxidant enzymes (CAT, GPx, SOD) in plasma following intraperitoneal administration of this substance in rat, and probably as an adaptive response to its pro-oxidant effects. This is in accordance with other study that also showed increase of CAT and SOD activity after acute application.11 However, decrease of plasma MDA level during the same period lead to the conclusion that there was an inverse response to the raise of antioxidant enzymes.

On the other hand, chronic application of Hcy induce drop in antioxidant enzymatic activity, ${ }^{22}$ probably due to increased time of exposure. Interestingly, in our investigation we have noticed reduced levels of MDA in almost all groups, and 
significantly increased levels of GPx in the same groups. It seems logic, considering that GPx by reducing $\mathrm{H}_{2} \mathrm{O}_{2}$ level, inhibit lipid peroxidation directly or indirectly by mediation of lipid peroxides. $^{23}$

During inhibition of gasotransmitter production, it has been observed increased activity of plasma antioxidant enzymes, indicating that $\mathrm{NO}, \mathrm{CO}$ or $\mathrm{H} 2 \mathrm{~S}$ could react with these enzymes in plasma. However, during inhibition of gaseous signaling molecules production, Hcy continues to potentiate raise in activity of SOD, CAT and GPX. These results showed no changes in dynamics of measured plasma antioxidants in presence or in absence of gasotransmitter synthesis alone, suggesting that the influences of Hcy are not quite clear. At the end, it is important to emphasize that determination of each gasotransmitter effect was assessed indirectly by their inhibition of production, which could be limitation of this study also. Addition of any data on mRNA and also cellular data would provide more evidence to the notion that enzyme involved in oxidative stress are induced or suppressed.

\section{CONCLUSION}

Gasotransmitters inhibitors increased significantly antioxidant enzymes activities and that increase was higher when they were administered in combination with Hcy. This indirectly indicates that gasotransmitters have an important role in oxidative stress protection.

\section{ACKNOWLEDGEMENTS}

This work was supported by the Ministry of Education, Science and Technological Development of Republic of Serbia, grant number 175043, and COST action CA16225 entitled "Realizing the therapeutic potential of novel cardioprotective therapies".

\section{CONFLICT OF INTEREST}

None.

\section{AUTHORSHIP STATEMENT}

Marko Djuric: performing of experimental procedures, statistical analysis, interpretation of data, preparation of the manuscript; Sanja Kostic: statistical analysis, interpretation of data, preparation of the manuscript; Dragana Loncar-Stojiljkovic: interpretation of data, analysis of results, preparation of the manuscript; Slavica Mutavdzin: statistical analysis, interpretation of data, preparation of the manuscript; Mirjana B Colovic: biochemical analysis; Danijela Krstic: biochemical analysis, interpretation of data; Predrag Stevanovic: interpretation of data, analysis of results; Dragan M Djuric: study design, performing of experimental procedures, statistical analysis, interpretation of data, analysis of results, preparation of the manuscript.

\section{REFERENCES}

1. Strain JJ, Dowey L, Ward M, Pentieva K, McNulty H. B-vitamins, homocysteine metabolism and CVD. Proc Nutr Soc 2004;63(4):597-603.

2. Schaffer A, Verdoia M, Cassetti E, Marino P, Suryapranata H, De Luca G. Novara Atherosclerosis Study Group (NAS). Relationship between homocysteine and coronary artery disease. Results from a large prospective cohort study. Thromb Res 2014;134(2):288-93.

3. Mujumdar VS, Tummalapalli CM, Aru GM, Tyagi SC. Mechanism of constrictive remodeling by homocysteine: role of PPAR. Am J Physiol Cell Physiol 2002;282:C1109-15.

4. Ungvari Z, Csiszar A, Edwards JG, et al. Increased superoxide production in coronary arteries in hyperhomocysteinemia. Role of tumor necrosis factor- $\alpha$, $\mathrm{NAD}(\mathrm{P}) \mathrm{H}$ oxidase, and inducible nitric oxide synthase. Arterioscler Thromb Vasc Biol 2003;23:418-23.

5. Derouiche F, Bôle-Feysot C, Naïmi D, Coëffier M. Hyperhomocysteinemia-induced oxidative stress differentially alters proteasome composition and activities in heart and aorta. Biochem Biophys Res Commun 2014;452(3):740-5.

6. Liu HH, Shih TS, Huang HR, Huang SC, Lee LH, Huang YC. Plasma homocysteine is associated with increased oxidative stress and antioxidant enzyme activity in welders. Sci World J 2013; e370487.

7. Gimenes R, Gimenes C, Rosa C.M, et al. Influence of apocynin on cardiac remodeling in rats with streptozotocin-induced diabetes mellitus. Cardiovasc Diabetol 2018; 17(1):15. doi: 10.1186/s12933-017-0657-9.

8. da Cunha AA, Scherer E, da Cunha MJ, et al. Acute hyperhomocysteinemia alters the coagulation system and oxidative status in the blood of rats. Mol Cell Biochem 2012;360(1-2):205-14.

9. Kerkeni M, Added F, Ben Farhat M, Miled A, Trivin F, Maaroufi K. Hyperhomocysteinaemia and parameters of antioxidative defence in Tunisian patients with coronary heart disease. Ann Clin Biochem 2008;45(2):193-8. 10. Wilcken DE, Wang XL, Adachi T, et al. Relationship 
between homocysteine and superoxide dismutase in homocystinuria: possible relevance to cardiovascular risk. Arterioscler Thromb Vasc Biol 2000;20(5):1199202.

11. Matté C, Mackedanz V, Stefanello FM, et al. Chronic hyperhomocysteinemia alters antioxidant defenses and increases DNA damage in brain and blood of rats: protective effect of folic acid. Neurochem Int 2009;54(1):7-13.

12. Wang R, editor. Signal transduction and the gasotransmitters: $\mathrm{NO}, \mathrm{CO}$ and $\mathrm{H} 2 \mathrm{~S}$ in biology and medicine. Humana Press, New Jersey, USA, 2004.

13. Zivkovic V, Jakovljevic V, Pechanova O, et al. Effects of DL-homocysteine thiolactone on cardiac contractility, coronary flow, and oxidative stress markers in the isolated rat heart: the role of different gasotransmitters. Biomed Res Int 2013; 2013:318471.

14. Aruoma OI, Halliwell B, Laughton MJ, Quinlan GJ, Gutteridge JMC. The mechanism of initiation of lipid peroxidation. Evidence against a requirement for an iron (II)- iron (III) complex. Biochemical Journal 1989;258:617-20.

15. Stamler JS, Osborne JA, Jaraki O, Rabbani LE, Mullins M, Singel D, et al. Adverse vascular effects of homocysteine are modulated by endothelium-derived relaxing factor and related oxides of nitrogen. J Clin Invest 1993;91:308-18.

16. Xu S, Liu Z, Liu P. Targeting hydrogen sulfide as a promising therapeutic strategy for atherosclerosis. Int J Cardiol 2014;172:313-17.

17. Kabil O, Motl N, Banerjee $\mathrm{R}$. $\mathrm{H}_{2} \mathrm{~S}$ and its role in redox signaling. Biochim Biophys Acta 2014;1844:1355-66.

18. Cebova M, Košutova M, Pechanova O. Cardiovascular Effects of Gasotransmitter Donors Physiol Res 2016;65 (Suppl. 3): S291-S307.

19. Beutler E. Catalase. In: Red cell metabolism, a manual of biochemical methods. E Beutler, editors. New York: Grune and Stratton; 1982, p. 105-6.

20. Misra HP, Fridovich I. The role of superoxide-anion in the autooxidation of epinephrine and a simple assay for superoxide dismutase. J Biol Chem 1972; 247: 3170-5.

21. Vives-Bauza C, Starkov A, Garcia-Arumi E. Measurements of the antioxidant enzyme activities of superoxide dismutase, catalase, and glutathione peroxidase. Methods Cell Biol 2007; 80:379-93.

22. Boyacioglu M, Sekkin S, Kum C, et al. The protective effects of vitamin $\mathrm{C}$ on the DNA damage, antioxidant defenses and aorta histopathology in chronic hyperhomocysteinemia induced rats. Exp Toxicol Pathol 2014; 66(9-10):407-13.

23. Kwiecien S, Jasnos K, Magierowski M, et al. Lipid peroxidation, reactive oxygen species and antioxidative factors in the pathogenesis of gastric mucosal lesions and mechanism of protection against oxidative stress - induced gastric injury. J Physiol Pharmacol 2014; 65(5):613-22. 